\title{
NIOBIUM AND TANTALUM SEPARATION BY GAS-PHASE FLUORINATION
}

\author{
A.D. Pienaar* ${ }^{1}$, J.B. Wagener ${ }^{1}$, and P.L Crouse ${ }^{2}$ \\ ${ }^{1}$ South African Nuclear Energy Corporation, P.O. Box 582, Pretoria 0001, South Africa \\ ${ }^{2}$ Department of Chemical Engineering, University of Pretoria, Pretoria 0002, South Africa \\ *Corresponding author: andrew.pienaar@necsa.co.za
}

\begin{abstract}
The separation of tantalum and niobium compounds has been of interest for many years, with few new developments. Classically separation is achieved by liquid-liquid extraction and most research focuses on optimizing this process. A separation method that bypasses the need for liquid-liquid extraction is reported here. The process uses dry fluorination to convert tantalum and niobium pentoxides into metal oxyfluorides. The thermal behaviour of these species are sufficiently different for separation to be achieved by preferential volatilisation. Experimental results indicate that at least two temperature ranges are suitable for separation, viz. one below $165^{\circ} \mathrm{C}$, and one above $650^{\circ} \mathrm{C}$.
\end{abstract}

Keywords: niobium tantalum separation, niobium oxyfluoride, tantalum oxyfluoride

\section{Introduction}

Niobium and tantalum are present in the crust of the earth at $1 \times 10^{-3}$ and $2 \times 10^{-4}$ wt \% respectively. They are encountered together in minerals, mostly in the form of tantalite or columbite(Agulyansky, 2004). Metal recovery is usually achieved by dissolving the mineral in aqueous HF, followed by liquid-liquid extraction.

The African continent accounts for about $19 \%$ of tantalum ore reserves (Salazar and McNutt, 2011), with the most significant deposits occurring in central Africa. While neither tantalum nor niobium is mined on a large scale in South Africa, up to 200 tonn es/month of unprocessed ore 
may reach South African borders from countries such as Zimbabwe, Mozambique and the rest of Africa. Thus, there is substantial local interest in processing minerals which contain these two metals.

Tantalum and niobium are industrially important materials due to their use in the fields of electronics, optics and nuclear energy (Moller, 1986). The major consumer of tantalum is the capacitor industry which has defined the industry standard for high purity tantalum production. Niobium is predominantly used in the manufacture of high-grade structural steel and super-alloys (Papp, 2006).

The uncanny chemical similarity between the two metals can be attributed to their virtually identical ionic sizes, resulting from lanthanide contraction (Nowak and Ziolek, 1999). This similarity, combined with their simultaneous occurrence in metal ores, makes refinement and separation of these metals troublesome and suggests the combined study of $\mathrm{Nb}(\mathrm{V})$ and $\mathrm{Ta}(\mathrm{V})$ compounds (Bayot and Villiers, 2006; Nagiev, 2004; Sadoway and Flengas, 1980).

Separation using liquid-liquid extraction has significant drawbacks since it involves the use of aqueous hydrofluoric acid as well as several organic solvents. The procedure generates a large amount of hazardous liquid waste that is difficult and expensive to store and process.

Naturally occurring tantalum and niobium occur in pentoxide form in mineral ores(Agulyansky, 2004). In this paper we present an alternative method for separating mixtures of tantalum and niobium pentoxide which employs gas-phase fluorination using anhydrous hydrogen fluoride. The metal pentoxides are converted to a mixture of dioxyfluorides and more highly fluorinated species. The differences in the thermal-decomposition/sublimation (we will use volatilisation when decomposition or sublimation is undefined) temperatures of these compounds allow thermal separation. An extensive literature search did not reveal any previous work based on this principle. 


\section{Experimental}

\subsection{Fluorination reactions}

Dilute HF(g) was prepared by loading a cylinder with 0.6 bar HF followed by $\mathrm{N}_{2}$ up to 6 bar. This yielded an $\mathrm{HF} / \mathrm{N}_{2}$ mixture of approximately 10 vol\%. A Setaram C80 calorimeter with Hastalloy sample holders, used as fluorination reaction vessels, was employed to monitor reaction heat flow. All experiments were conducted under constant nitrogen purge and the HF mixture was introduced into the purge gas at $95 \mathrm{std} \mathrm{ml}^{\mathrm{min}}{ }^{-1}$ once thermal equilibrium was achieved.

For single component experiments, both $\mathrm{Ta}_{2} \mathrm{O}_{5}$ (Alfa Aeser, $99.9 \%$ ) and $\mathrm{Nb}_{2} \mathrm{O}_{5}$ (Alfa Aeser, $99.9 \%$ were first treated with $\mathrm{HF}(\mathrm{g})$ at $30^{\circ} \mathrm{C}$, to get an indication of reaction products. The effect of temperature on the fluorination reaction in mixtures of these oxides was then studied by varying the temperature from $30{ }^{\circ} \mathrm{C}$ to $60{ }^{\circ} \mathrm{C}$ in several separate experiments. Flow rate of the purge gas was also varied between 30 and $100 \mathrm{ml} \mathrm{min}^{-1}$. For experiments using oxide mixtures, compositions are found in Table 1, and operating parameters for both the fluorination and separation steps can be found in Table 2 .

Product distributions were determined by selective sublimation and decomposition of the product at selected temperatures using a TA Instruments QDT 600 simultaneous TG/DSC. The metal content of each product was determined by ICP-OES analysis.

Table 1 Mixtures of tantalum and niobium pentoxide prepared for separation

\begin{tabular}{ccc}
\hline Mixture & $\begin{array}{c}\mathbf{T a}_{2} \mathbf{O}_{5} \\
(\mathbf{g})\end{array}$ & $\begin{array}{c}\mathbf{N b}_{2} \mathbf{O}_{\mathbf{5}} \\
\mathbf{( g )}\end{array}$ \\
\hline $\mathbf{1}$ & 1.356 & 1.188 \\
$\mathbf{2}$ & 0.366 & 0.343 \\
\hline
\end{tabular}


Table 2 Operating parameters for fluorination experiments

\begin{tabular}{cccc}
\hline Experiment & Mix & $\begin{array}{c}\mathbf{N}_{\mathbf{2}} \text { Flow } \\
\left(\mathbf{m l . m i n}^{-\mathbf{1}}\right)\end{array}$ & $\begin{array}{c}\text { Fluorinating } \\
\text { Temp }\left({ }^{\mathbf{0}} \mathbf{C}\right)\end{array}$ \\
\hline 1 & 1 & 100 & 40 \\
2 & 1 & 100 & 40 \\
3 & 1 & 50 & 40 \\
4 & 2 & 50 & 60 \\
5 & 2 & 50 & 30 \\
\hline
\end{tabular}

\subsection{Preparation of model compounds}

The oxyfluorides $\left(\mathrm{MO}_{2} \mathrm{~F}\right.$ and $\left.\mathrm{MOF}_{3}\right)$ of both niobium and tantalum were prepared according to the procedure used by Köhler (Köhler et al., 2002). The metal pentoxide was dissolved in 40\% HF(aq) aided by microwave digestion. After filtration a powdery white product was obtained and dried at $150{ }^{\circ} \mathrm{C}$ overnight. XRD analysis (not shown) showed that $\mathrm{MO}_{2} \mathrm{~F}$ was the only crystalline phase present for both the niobium and tantalum products using this technique.

Subsequent preparation of oxy-trifluorides $\left(\mathrm{MOF}_{3}\right)$ was done by the reaction of $\mathrm{MF}_{5}$ with the $\mathrm{MO}_{2} \mathrm{~F}$ species, as described by the following reaction equations:

$\mathrm{NbO}_{2} \mathrm{~F}(0.401 \mathrm{~g})+\mathrm{NbF}_{5}(0.623 \mathrm{~g}) \rightarrow 2 \mathrm{NbOF}_{3}$

$\mathrm{TaO}_{2} \mathrm{~F}(0.405 \mathrm{~g})+\mathrm{TaF}_{5}(0.478 \mathrm{~g}) \quad \rightarrow 2 \mathrm{TaOF}_{3}$

These reactions were completed in sealed Hastalloy C80 sample vessels by adding a mechanically mixed excess (ca. 20\%) of $\mathrm{MF}_{5}$ to $\mathrm{MO}_{2} \mathrm{~F}$ and heating the vessel to $200{ }^{\circ} \mathrm{C}$. After two hours at this temperature, the vessel was cooled and XRD patterns (Figures 1a and b) were collected. From these diffractograms the only crystalline phases that could be identified were $\mathrm{MO}_{2} \mathrm{~F}$ and $\mathrm{MOF}_{3}$. Thermogravimetric measurements were performed on a TA Instruments SDT Q600. The experimentally determined volatilisation temperatures of these four species, along with the sublimation temperature of the commercially available pentafluorides, are given in Table 3. 
Table 3 Experimental volatillisation temperatures of prepared oxyfluoride species and pentafluorides.

\begin{tabular}{ccc}
\hline & $\begin{array}{c}\text { M }=\mathbf{N b} \\
\left({ }^{\circ} \mathbf{C}\right)\end{array}$ & $\begin{array}{c}\text { M }=\text { Ta } \\
\left({ }^{\circ} \mathbf{C}\right)\end{array}$ \\
\hline $\mathbf{M O}_{2} \mathbf{F}$ & 651 & 720 \\
$\mathbf{M O F}_{3}$ & 223 & 272 \\
$\mathbf{M F}_{\mathbf{5}}$ (Alfa Aeser) & 80 & 96 \\
\hline
\end{tabular}

\section{Results and Discussion}

In practice, the preparation of a single oxyfluoride is problematic since the higher fluorinated species are prone to hydrolysis (Cordier et al., 2004) and in turn the oxygen-rich species may be fluorinated by the fluorine-rich ones. As a consequence, preparation of a single species often results in a mixture of different oxyfluorides.

\subsection{Single component reactions}

The reactions between $\mathrm{HF}(\mathrm{g})$ and niobium and tantalum pentoxide are characterised by two consecutive exothermic events (Figure 1). For the reaction between tantalum pentoxide and $\mathrm{HF}(\mathrm{g})$, the second exotherm is less intense, but broader than that observed for niobium pentoxide.

Thermodynamically the metal pentafluorides are the stable products for the reactions between the metal pentoxides and anhydrous HF at relatively low temperatures, i.e. for the substitution reactions:

$\mathrm{M}_{2} \mathrm{O}_{5(\mathrm{~s})}+10 \mathrm{HF}_{(\mathrm{g})} \rightarrow 2 \mathrm{MF}_{5(\mathrm{~s})}+5 \mathrm{H}_{2} \mathrm{O}_{(\mathrm{l})}$ 


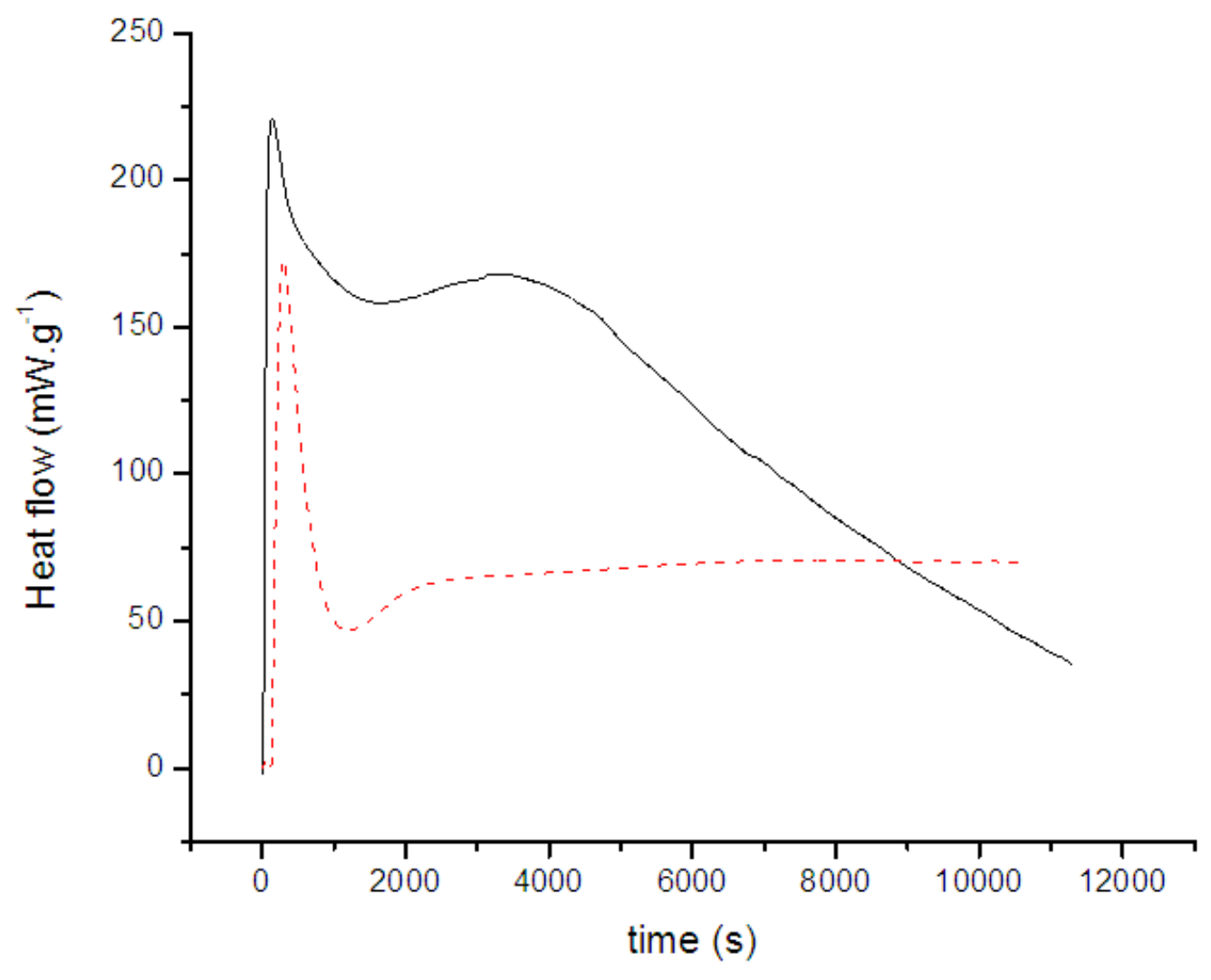

Figure 1 DSC heat flow observed during the reaction of niobium pentoxide (solid line) and tantalum pentoxide (dashed line) with anhydrous $\mathrm{HF}$ at $30^{\circ} \mathrm{C}$

For Ta and Nb the values for the change in standard Gibbs energy at room temperature are 101.5 and $-64.2 \mathrm{~kJ} \mathrm{~mol}^{-1}$ respectively, calculated from the data base in HSC Chemistry v6.0 (Outotec Research Oy, 2006). Clearly, however, there is a kinetic barrier to achieving full fluorination in each case, as will be shown below.

A two step reaction, with oxyfluoride intermediates, is similarly observed when elemental fluorine is used as the fluorinating agent (Rakov et al., 1971):

$\mathrm{Nb}_{2} \mathrm{O}_{5}+\mathrm{F}_{2} \quad \rightarrow 2 \mathrm{NbO}_{2} \mathrm{~F}+1 / 2 \mathrm{O}_{2}$

$\mathrm{NbO}_{2} \mathrm{~F}+2 \mathrm{~F}_{2} \rightarrow \mathrm{NbF}_{5}+\mathrm{O}_{2}$ 
Using TG data collected for the prepared model compounds and comparison of XRD data in the PDF-2007 data base, we were able to identify the species noted in Table 4 below after HF treatment at $30^{\circ} \mathrm{C}$.

Table 4 Products identified using the 2007-PDF-2 database for the reaction between $\mathrm{M}_{2} \mathrm{O}_{5}$ and $\mathrm{HF}(\mathrm{g})$

\begin{tabular}{cc}
\hline $\mathbf{M}=\mathbf{N b}$ & $\mathbf{M}=\mathbf{T a}$ \\
\hline $\mathrm{NbO}_{2} \mathrm{~F}$ & $\mathrm{TaO}_{2} \mathrm{~F}$ \\
$\mathrm{NbOF}_{3}$ & $\mathrm{TaOF}_{3}$ \\
$\mathrm{Nb}_{2} \mathrm{O}_{5}$ & $\mathrm{Ta}_{3} \mathrm{O}_{7} \mathrm{~F}$ \\
& $\mathrm{Ta}_{2} \mathrm{O}_{5}$ \\
\hline
\end{tabular}

Figure 3 shows the decomposition profiles for the fluorination products of $\mathrm{Ta}_{2} \mathrm{O}_{5}$ and $\mathrm{Nb}_{2} \mathrm{O}_{5}$. Below $120^{\circ} \mathrm{C}$, removal of any adsorbed HF and any possible pentafluorides, or other highly fluorinated species, occurs. Next, at $148^{\circ} \mathrm{C}$, volatilisation of a niobium species occurs. This oxyfluoride could not be identified from the collected XRD or TG data. After that $\mathrm{TaOF}_{3}(\mathrm{~g})$ sublimates at $272{ }^{\circ} \mathrm{C}$, and decomposition of niobium dioxyfluoride $\left(\mathrm{NbO}_{2} \mathrm{~F}\right)$ and tantalum dioxyfluoride $\left(\mathrm{TaO}_{2} \mathrm{~F}\right)$ follow at 651 and $720{ }^{\circ} \mathrm{C}$ respectively. Varying the time that the pentoxides are exposed to HF and comparing the resulting products allowed us to postulate the following reaction steps:

$$
\begin{aligned}
& \mathrm{M}_{2} \mathrm{O}_{5}+\mathrm{yHF} \rightarrow \mathrm{M}_{2} \mathrm{O}_{5} \cdot \mathrm{xHF}+(\mathrm{y}-\mathrm{x}) \mathrm{HF}(\mathrm{g}) \\
& \mathrm{M}_{2} \mathrm{O}_{5} \cdot \mathrm{xHF}+(2-\mathrm{x}) \mathrm{HF} \rightarrow 2 \mathrm{MO}_{2} \mathrm{~F}+\mathrm{H}_{2} \mathrm{O} \\
& \mathrm{MO}_{2} \mathrm{~F}+2 \mathrm{HF} \leftrightarrow \mathrm{MOF}_{3}+\mathrm{H}_{2} \mathrm{O} \\
& \mathrm{MOF}_{3}+(2-2 \mathrm{y}) \mathrm{HF} \rightarrow \mathrm{MO}_{\mathrm{y}} \mathrm{F}_{5-2 \mathrm{y}}+\mathrm{H}_{2} \mathrm{O}
\end{aligned}
$$




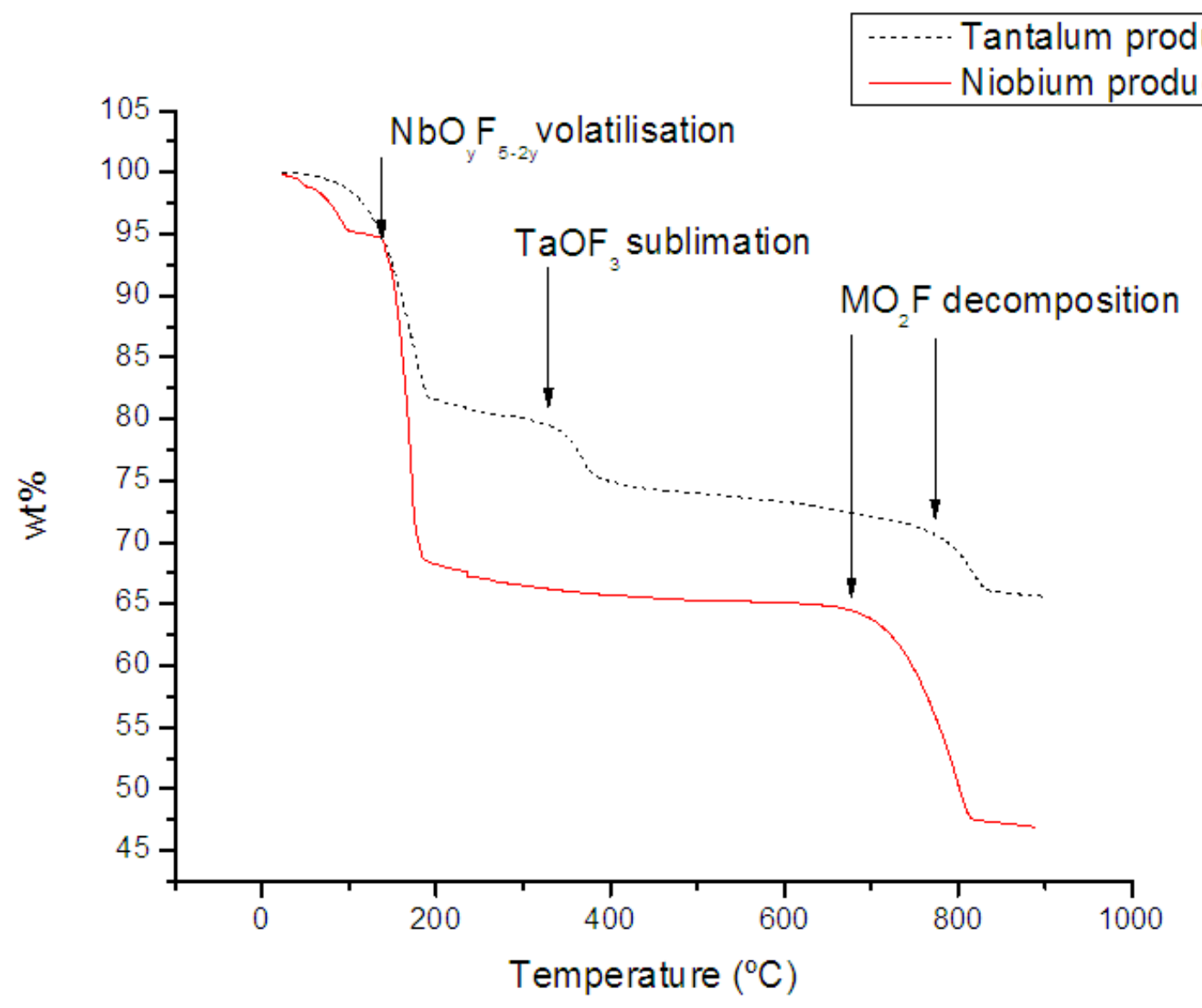

Figure 3 Thermal decomposition of the HF-flruorination products of tantalum and niobium oxide

In the above $0 \leq \mathrm{y} \leq 1$. Formation of species more fluorinated than $\mathrm{MO}_{2} \mathrm{~F}$ occurs slowly and accounts for the slow decrease in heat flow seen on Figure 2, an elegant explanation for the deviation of Gaussian symmetry for the second reaction peak. Once the reaction is complete, a mixture of the dioxyfluoride, oxy trifluoride, and more fluorinated compounds exists.

Figure 4, the first derivative of TG data, summarizes the recorded sublimation/decomposition temperatures of the identified HF fluorination products as well as the commercial pentafluoride samples. The most fluorinated of the compounds, the pentafluorides, start sublimation below 100 ${ }^{\circ} \mathrm{C}$, followed by volatilisation of $\mathrm{MOF}_{3}$ and finally the dioxyfluoride species decomposes at 655 $(\mathrm{M}=\mathrm{Nb})$ and $720^{\circ} \mathrm{C}(\mathrm{M}=\mathrm{Ta})$. Kodama and Goto (Kodama and Goto, 1975) determined the decomposition reaction for $\mathrm{NbO}_{2} \mathrm{~F}$ to proceed according to the reaction: 


$$
4 \mathrm{NbO}_{2} \mathrm{~F}(\mathrm{~s}) \rightarrow \mathrm{Nb}_{3} \mathrm{O}_{7} \mathrm{~F}(\mathrm{~s})+\mathrm{NbOF}_{3}(\mathrm{~g})
$$

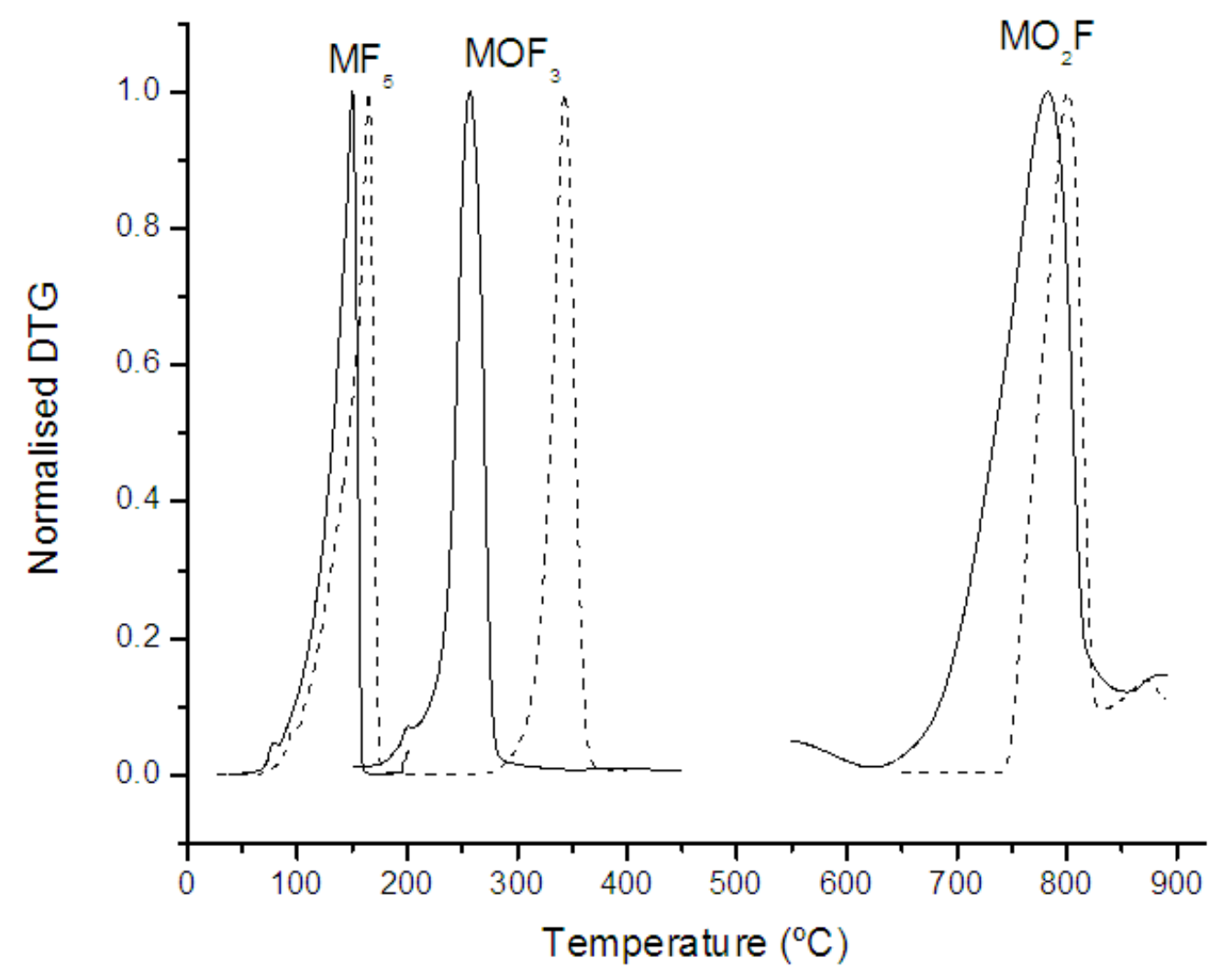

Figure 4 Normalised DTG curve for products of niobium (solid line) and tantalum (dashed line) pentoxide treated with $\mathrm{HF}(\mathrm{g})$, also sublimation of commercially bought pentafluorides

According to the literature, and our own experiments, the sublimation temperatures of niobium pentafluoride $\left(80^{\circ} \mathrm{C}\right)$ and tantalum pentafluoride $\left(96.8^{\circ} \mathrm{C}\right)$ are $15^{\circ} \mathrm{C}$ apart and could in theory be used for separation, using a thermal process.

From the data presented in Figure 4 it can be seen that this is not feasible since significant overlap occurs and near perfect temperature control would be required - especially for larger samples. If on the other hand the dioxyfluorides were targeted, separation might be possible, but the high temperature above $650{ }^{\circ} \mathrm{C}$ will have a substantial process cost impact. The most favourable set of oxyfluorides to target would be therefore be $\mathrm{TaOF}_{3} / \mathrm{NbO}_{\mathrm{y}} \mathrm{F}_{5-2 \mathrm{y}}$, for which the 
niobium species sublimates at about $148{ }^{\circ} \mathrm{C}$ and the tantalum analogue only at $272{ }^{\circ} \mathrm{C}$. Alternatively, if both compounds could be converted to oxy trifluorides, a separation via this set could also be possible.

\subsection{Reaction of mixtures}

The HF fluorination of mixtures of $\mathrm{Nb}_{2} \mathrm{O}_{5}$ and $\mathrm{Ta}_{2} \mathrm{O}_{5}$ showed similar heat-flow profiles to that observed for single component experiments (Figure 5). The products of these runs were heated to $165{ }^{\circ} \mathrm{C}$ where the temperature was maintained for 30 minutes. At this temperature, after evolution of volatiles, only $\mathrm{NbO}_{\mathrm{y}} \mathrm{F}_{5-2 \mathrm{y}}$ is expected to sublimate, leaving the majority of tantalum values in the solid phase (Table 5).

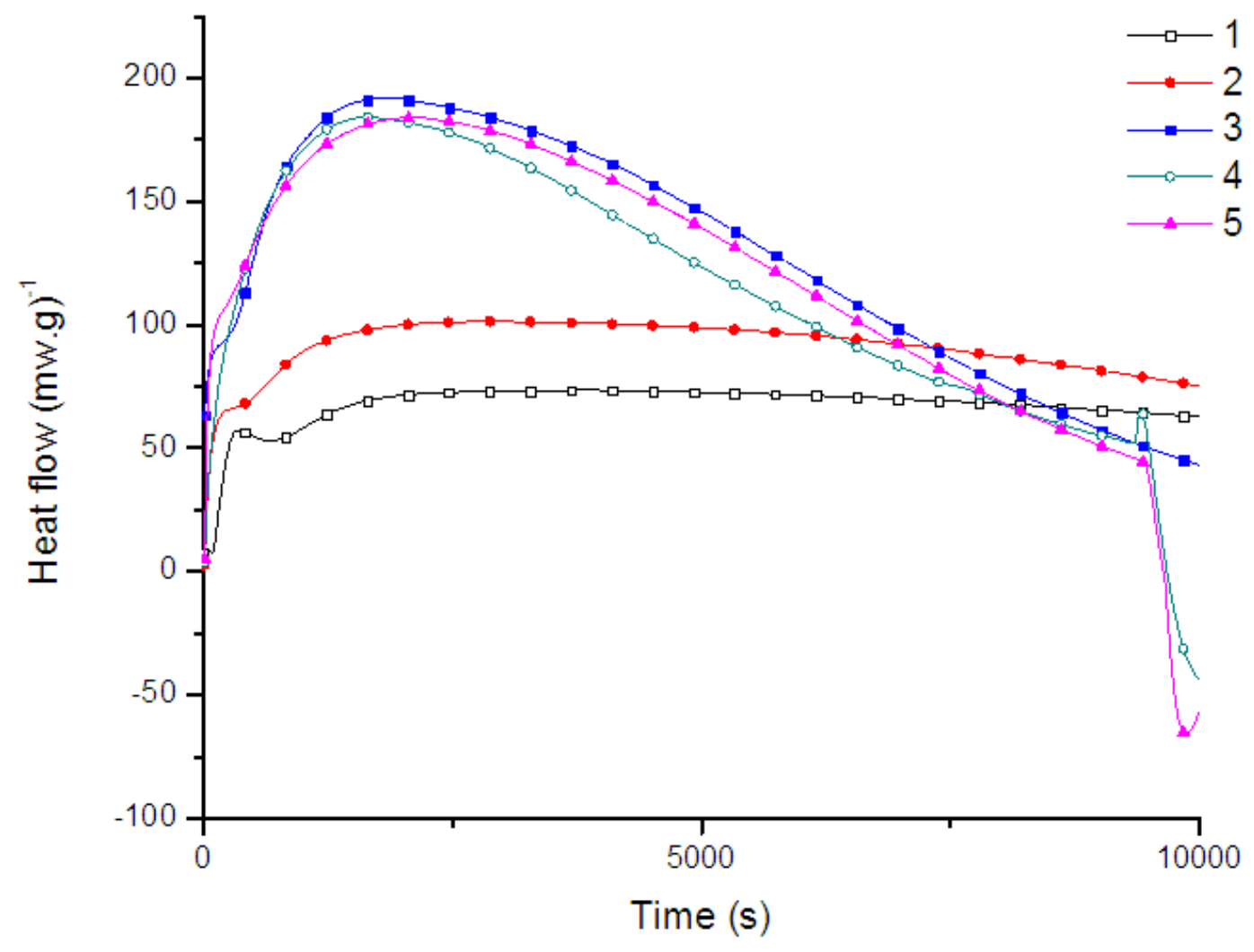

Figure 5 DSC heat flow observed during $\mathrm{HF}(\mathrm{g})$ fluorination experiments 1 to 5 
Table 5 Mass ratio of Ta:Nb according to ICP results before and after each experiment

\begin{tabular}{ccc}
\hline & \multicolumn{2}{c}{ Nb:Ta Ratio } \\
Experiment & Before & After \\
\hline 1 & 0.74 & 0.56 \\
2 & 0.74 & 0.59 \\
3 & 0.85 & 0.74 \\
4 & 0.99 & 0.77 \\
5 & 0.99 & 0.80 \\
\hline
\end{tabular}

\section{Conclusion}

By treating mixtures of tantalum and niobium pentoxide with $\mathrm{HF}(\mathrm{g})$, a mixture of oxyfluoride compounds is created. Though the thermal behaviour of the pentoxides and pentafluorides of tantalum and niobium is similar, the oxyfluorides have substantially different sublimation and decomposition temperatures. This difference allows for a separation process that does not involve the use of aqueous HF or organic solvents. Indeed, we have shown that such a separation is possible at $165^{\circ} \mathrm{C}$.

Further work may include optimising experimental parameters to produce the desired oxyfluoride species, which may make an even more efficient process possible. Since both tantalum and niobium occur in nature in pentoxide form, this process could be extended to recover metal values from minerals. A patent application for this process has been filed (Wagener et al., 2011).

\section{References}

Agulyansky, A., 2004. The Chemistry of Tantalum and Niobium Fluoride Compounds. Elsevier, Amsterdam.

Bayot, D. and Villiers, M.d., 2006. Peroxo complexes of niobium(V) and tantalum(V). Coord. Chem. Rev., 250: 2610. 
Cordier, S., Roisnel, T. and Poulain, M., 2004. Synthesis and characterization of the novel $\mathrm{Nb}_{3} \mathrm{O}_{5} \mathrm{~F}_{5}$ niobium oxyfluoride: the term $\mathrm{n}=3$ of the $\mathrm{Nb}_{\mathrm{n}} \mathrm{O}_{2 \mathrm{n}-1} \mathrm{~F}_{\mathrm{n}+2}$ series J. Solid State Chem., 177: 3119-3126.

Kodama, H. and Goto, M., 1975. The thermal decomposition of $\mathrm{Nb}_{3} \mathrm{O}_{7} \mathrm{Cl}$ and $\mathrm{NbO}_{2} \mathrm{~F}$. Z. Anorg. Allg. Chem., 415: 185.

Köhler, J. et al., 2002. Structures and Properties of $\mathrm{NbOF}_{3}$ and $\mathrm{TaOF}_{3}$ - with a Remark to the O/F Ordering in the $\mathrm{SnF}_{4}$ Type Structure. Z. Anorg. Allg. Chem., 628: 2683.

Moller, P., 1986. Lanthanides, Tantalum and Niobium, Verlag. . Special Publication No. 7 of the Society for Geology Applied to Mineral Deposits. P1. Springer, Berlin.

Nagiev, K.D., 2004. Spectrophotometric Determination of Simultaneously Present Niobium and Tantalum. Journal of Analytical Chemistry, 59: 930.

Nowak, I. and Ziolek, M., 1999. Niobium Compounds: Preparation, Characterization, and Application in Heterogeneous Catalysis. 99: 3603-3624.

Papp, J.F., 2006. Columbium.

Rakov, E.G., Kopchikhin, D.S., Sudarikov, B.N. and Gromov, B.V., 1971. Fluorination kinetics of $\mathrm{Nb}_{2} \mathrm{O}_{5}$. Atomnaya Energiya, 31: 137.

Sadoway, R.D. and Flengas, S.N., 1980. A new process for the separation of Tantalum from Niobium. Metal. Trans. B, 11: 57.

Salazar, K. and McNutt, M.K., 2011. Mineral Commodity Summaries 2011, U.S. Geological Survey.

Wagener, J.B., Pienaar, A.D. and Carstens, P.A.B., 2011. Treatment of tantalum -and/or niobium containing compounds South Africa. 